\title{
Razón y cultura: una crítica a la hermenéutica constitucional moderna desde la interpretación dialógica*
}

\author{
Reason and culture: a critique of modern \\ constitutional hermeneutics from dialogic \\ interpretation
}

\section{Claudia Storini ${ }^{* *}$}

\section{RESUMEN}

A través del análisis crítico de la teoría de la interpretación entendida como limite a los poderes de los últimos intérpretes de la Constitución, este trabajo intenta evidenciar la inexistencia, por una parte, de algunos de los más importantes baluartes sobre los que se funda el Estado constitucional moderno; por otra, la de la neutralidad argumentativa y de una razón pura. Por tanto, evidencia también la necesidad de que los juristas, recogiendo el espiritu de la crítica juridica como instrumento de análisis para dignificar nuestra convivencia social, den sustento a un nuevo Estado constitucional basado en el verdadero respeto de la pluralidad y del principio democrático.

PALABRAS CLAVE: Teoria de la interpretación, post-positivismo, interpretación postmoderna, pluralismo.

\begin{abstract}
Through critical analysis of the theory of interpretation understood as limited by the powers of the past interpreters of the Constitution, this paper attempts to demonstrate, on the one hand, the absence of some of the most important bastions on which the modern constitutional State is founded. On the other hand, this paper also wants to demonstrate the lack of neutrality and pure argumentative reason, and therefore the need for lawyers, who utilizing the spirit of legal criticism as an analytical tool to dignify our social life, could sustain a new constitutional State based on true respect for plurality and democratic principle.
\end{abstract}

KEY WORDS: Theory of interpretation, post-positivism, postmodern interpretation pluralism.

\footnotetext{
* Recibido: 27 de julio de 2015. Aceptado: 31 de agosto de 2015.

**Profesora Titular de la Universidad Pública de Navarra, España. (claudia.f.storini@gmail.com)
} 


\section{SUMARIO}

1. Introducción

2. Limites de la hermenéutica positivista

3. Método, teoria del derecho e interpretación constitucional

4. Teorías deductivo-demostrativas y tópico-retóricas y naturaleza de la decisión del Tribunal Constitucional

5. A modo de conclusión: interpretación dialógica y finalidad de la motivación de la sentencia constitucional

El poder simbólico como poder de constituir lo dado por la enunciación, de hacer ver y de hacer creer, de confirmar o de transformar la visión del mundo, por lo tanto el mundo; poder casi mágico que permite obtener el equivalente de lo que es obtenido por la fuerza (física o económica), gracias al efecto específico de movilización, no se ejerce sino él es reconocido, es decir, desconocido como arbitrario (Pierre Bourdieu, Sobre el poder simbólico).

\section{Introducción}

La progresiva desnaturalización de las originarias funciones atribuidas al Tribunal Constitucional es un tema tan debatido en doctrina que resultaría inútil, en este contexto, recapitular las críticas que le han acompañado.

Este órgano, que nació para desarrollar la que debió ser una labor jurisdiccional aséptica, ha llegado a configurarse como partícipe, en muchas ocasiones, del proceso legislativo. El simple análisis de los fallos de algunas de sus sentencias demuestra la progresiva acentuación de las características normativas de la labor del Tribunal y su creciente afırmación como interlocutor privilegiado del Parlamento en el proceso de formación y aplicación de sus decisiones normativas fundamentales. ${ }^{1}$

\footnotetext{
${ }^{1}$ Sin entrar en el amplio debate acerca de las sentencias interpretativas, baste con hacer referencia a las sentencias denominadas por la doctrina "manipulativas". Dichas sentencias pueden ser de tres tipos. En primer lugar, las reductoras; es decir, aquellas que reducen el contenido normativo del texto de la disposición interpretada. En segundo, las sustitutivas, en las cuales el Tribunal Constitucional sustituye parte del contenido normativo de un precepto por otro contenido en uno de los fundamentos jurídicos. Finalmente, en las sentencias aditivas el Tribunal incluye "algo" no previsto en la disposición objeto de juicio con el fin de hacerla conforme con la Constitución. En la doctrina, véanse, por ejemplo, Ezouiaga Ganuzas, Francisco Javier. "Diez años de fallos constitucionales (sentencias interpretativas y poder normativo del Tribunal Constitucional)", Revista Vasca de Administración Pública, No. 31, 1991, pp. 117142; Gutiérrez Zarza, Maria Ángeles. "Las sentencias interpretativas y aditivas del Tribunal Constitucional español", Revista de Derecho Procesal, No. 3, 1995, pp. 187-204; Diaz Revorio, Francisco Javier. Las Sentencias interpretativas del Tribunal Constitucional: significado, tipología, efectos y legitimidad; análisis especial de las sentencias aditivas, Lex Nova, Valladolid, 2001.
} 
El renovado papel del Tribunal Constitucional, su progresiva expansión y su función sustancialmente normativa ya no pueden justificarse con la imagen, hábilmente esbozada en la doctrina, de una legislación de "rimas obligadas", con la cual se intentó contemperar el método parajudicial del Alto Tribunal y las consecuencias sustancialmente normativas de algunas de sus decisiones. ${ }^{2}$ La jurisprudencia constitucional demuestra que sólo con una buena dosis de ingenuidad podría todavía sostenerse que las sentencias normativas del Tribunal son el mero resultado de una interpretación mecánica impuesta por la "métrica" de las normas constitucionales. Es evidente que en muchas ocasiones se trata de una elección conscientemente adoptada por este órgano frente a una multitud de soluciones posibles. ${ }^{3}$

El inevitable; implícito en sus mismas premisas, el desarrollo del principio de legalidad (esto es, la afırmación de las constituciones rígidas garantizadas) tiende a desplazar el baricentro del ordenamiento jurídico desde el Parlamento al órgano de justicia constitucional, y aunque la ley siga siendo el principal acto normativo en el sistema de las fuentes, esto será así tan sólo dentro de los límites impuestos por el Tribunal a través de sus decisiones inmodificables. Todo ello ha llevado la doctrina a auspiciar la elaboración de una teoría de la división de poderes más adecuada a la realidad de la justicia constitucional. ${ }^{4}$ Tanto la crisis del Parlamento, como la expansión de las capacidades normativas de los Tribunales Constitucionales ya no pueden calificarse como fenómenos contingentes o territorialmente aislados. Para poder justificarlos, se hace necesario reconsiderar los conceptos de "forma de Estado" y "de gobierno" en relación con la actual experiencia constitucional para revisar la posición en ellos asignada a los Tribunales Constitucionales.

Además, si se considera que los órganos de justicia constitucional no son órganos democráticamente legitimados, en el sentido de que sus miembros no poseen adecuados canales de conexión con la sociedad civil (de la cual no

\footnotetext{
${ }^{2}$ Crisafulu, Vezıo. Lezioni di Diritto Costituzionale, Cedam, Padua, 1978, Vol. II, p. 363 y ss.

${ }^{3}$ Muchos de los fallos interpretativos han sido acompañados de votos particulares que, criticando la inadecuada utilización de estas técnicas, demuestran la existencia de otras vías interpretativas; por ejemplo, en caso español, STc 50/1999 (Régimen jurídico de las Administraciones Publicas), voto particular del magistrado C. Viver Pi-Sunyer; 176/1999 (Comarcas del Ebro), voto particular del magistrado V. Conde Martín de Hijas; 74/2000, (Ley Murciana de Promoción y Participación Juvenil), voto particular del magistrado V. Conde Martín de Hijas.

${ }^{4}$ Aja, Eliseo y González Bellfuss, Markus. "Conclusiones Generales", en Aja, Eliseo (ed.), Las tensiones entre el Tribunal Constitucional y el Legislador en la Europa actual, Ariel, Barcelona, 1998, pp. 258-263. Es indicativo a este respecto que Acosta Sánchez, tratando las diferentes explicaciones doctrinales de la jurisdicción constitucional, incluya entre las "explicaciones exorbitantes" la consideración de la jurisdicción constitucional como "tercera Cámara". Acosta Sánchez. Formación de la Constitución y Jurisdicción Constitucional, Tecnos, Madrid, 1998, p. 362; Habermas, en cambio, parece abogar por un sistema de justicia constitucional distinto del que hoy se conoce tanto en Europa como en Estados Unidos. Habermas, Jürgen. Facticidad y validez, Trota, Madrid, 1998.
} 
pueden considerarse representativos, sino a través de una mediación institucional ambigua y, generalmente, no electiva), sus decisiones, desprovistas de una base consensuada preventiva, deben traer aliunde la capacidad de incidir eficazmente en la sociedad y autoafirmarse en relación con las diferentes determinaciones tomadas por el Parlamento.

Ya no es suficiente defender la jurisdicción constitucional como "alteración necesaria”, es decir, responder al problema de la falta de legitimidad de un órgano capaz de crear normas sosteniendo que "si se observan las cosas serenamente la justicia constitucional no representa tanto una antinomia sino más bien una alteración del esquema democrático-parlamentario, pero una alteración intencionalmente puesta por el constituyente en función de un preciso diseño político [...] en el que la falta de legitimidad democrática que caracteriza la jurisdicción constitucional es inevitable y en alguna medida necesaria, a fin de asegurar la efectiva separación del controlador respecto al controlado". ${ }^{5}$ No es suficiente porque esta justificación se basa sobre la equivocada consideración de las sentencias normativas del Tribunal como el resultado de las "rimas obligadas" impuestas por las normas constitucionales. ${ }^{6}$

Frente a la falta de operatividad de los límites puestos a la actividad del Tribunal Constitucional y ante la imposibilidad de volver atrás en la expansión del papel "positivo" desarrollado por este órgano, se abre un espacio en la doctrina para un replanteamiento de las relaciones entre el juez de la constitucionalidad y el Parlamento, auspiciando la configuración de una superior colaboración entre ellos. ${ }^{7}$ Según este planteamiento, el núcleo esencial de la problemática relacionada con la legitimidad del Tribunal Constitucional arranca de la existencia de sentencias que suponen la creación de normas. Por tanto, su solución sólo puede pasar por el reconocimiento de la necesidad de crear cauces constitucionales o legales distintos de los tradicionales y capaces de legitimarlas.

Así las cosas, si cabe admitir que los Tribunales Constitucionales continúen actuando como legislador positivo, es preciso construir una serie de límites a esta función. Además (y sin querer disminuir la relevancia de estos planteamientos), debe evidenciarse que estos mismos parecen desatender la consecuencia más relevante de la extensión de las funciones del juez de la constitucionalidad,

\footnotetext{
${ }^{5}$ Crisafulu, Vezio. "La Corte Costituzionale ha vent'anni", en Nicola Occhiocupo (Dir.), La Corte Costituzionale tra norma giuridica e realtá sociale. Bilancio di vent'anni di attivitá, II Mulino, Bolonia, 1978, pp. 72 y 73.

${ }^{6}$ CrISAFULI, VezIo. Lezioni di Diritto Costituzionale, op. cit., p. 363.

${ }^{7}$ Aja, Eliseo y González Bellfuss, Markus. "Conclusiones Generales", en Aja, Eliseo (Ed.), Las tensiones entre el Tribunal Constitucional y el Legislador en la Europa actual, op. cit., p. 290.
} 
que, entrando plenamente en el campo de la creación jurídica, se ha convertido de hecho en legislador constituyente. ${ }^{8}$

Las críticas a la utilización de esta definición -que podría ser equiparada por sus efectos a la de "poder constituyente continuo", o parangonarse con la de "comisionado del poder constituyente o constituyente permanente"- la cual plantea la falta de respeto hacia el principio democrático, y con ello la pérdida de toda significación de la idea de supremacía y rigidez constitucional, ${ }^{9}$ podrían reconducirse dentro del esquema del ejercicio democrático de los poderes constituidos, defendiendo que la legitimación de los Tribunales Constitucionales tan sólo podría descansar en la posibilidad de evaluar jurídicamente sus interpretaciones.

Es decir, en la capacidad de controlar que dicho órgano cumpla la necesaria función de adaptación de la Constitución formal a la realidad social utilizando instrumentos puestos a su alcance por el propio ordenamiento jurídico y, sobre todo, con la demanda de utilización de:

paradigmas deliberativos con las razones múltiples que subsisten en la comunidad. No sólo de razones propias, sino mediadas por legítimas razones plurales. Las razones argumentativas pueden desarrollarse desde el reconocimiento de que nuestras sociedades son pluriculturales y multiétnicas. [...] falta crear esferas públicas de discusión, donde se suscite un intercambio fraterno e incluyente de identidades, de culturas, de saberes, porque esto es lo que hará viable la existencia de sociedades donde se defiendan contenidos de respeto para cada cual y de la responsabilidad solidaria universal de uno para con el otro. ${ }^{10}$

\section{Limites de la hermenéutica positivista}

El presupuesto según el cual si bien el Tribunal Constitucional no dispone de una legitimación popular directa, sus decisiones pueden considerarse legítimas en la medida en que se configuren como decisiones jurídicas y no políticas, convierte la demostración del carácter jurisdiccional de este órgano en la fuente principal de su legitimación. Para ello, será necesario estudiar el cumplimento por el Tribunal Constitucional de las características del control jurisdiccional,

\footnotetext{
${ }^{8}$ Blanco Valdés define al Tribunal Constitucional como "legislador constituyente". Ibidem, p. 22.

${ }^{9}$ De Vega, Pedro. La reforma constitucional y la problemática del poder constituyente, Tecnos, Madrid, 1985, pp. 49 y sS.

${ }^{10}$ Córdoba, Paúl. Derecho procesal constitucional. Estudios críticos de doctrina, dogmática, argumentación y jurisprudencia, Corporación de Estudios y Publicaciones, Quito, 2016, p. 383.
} 
es decir, verificar, en primer lugar, el carácter objetivo del parámetro, $\mathrm{y}$, en segundo, el carácter objetivado del canon de valoración del propio parámetro.

En relación con el primero de estos dos elementos, el análisis de las disposiciones constitucionales demuestra que su peculiar conformación no permite, desde un punto de vista teórico-normativo, la objetivación del parámetro de control. En este contexto -siendo la Constitución un conjunto de disposiciones que, por lo general, se concretan a través de la interpretación-, puede llegarse a defender que la motivación proporcionada por el Tribunal Constitucional en sus decisiones alcanza una especial relevancia.

Dicha motivación, en cuanto relación entre argumentación y decisión, será el único instrumento que permita -en la medida en que dicha concreción sea posible- establecer si el parámetro de control es o no un parámetro objetivo. La condición jurisdiccional del control de constitucionalidad dependerá, por tanto, de un único elemento: la demostración de la existencia de criterios objetivos de interpretación que vinculen la labor realizada por el Tribunal Constitucional.

A estas conclusiones -que implican la obligada relevancia de la reconstrucción de las operaciones desarrolladas por el juez a la hora de aplicar las disposiciones normativas- pudo llegarse a través de una dura confrontación con aquel "sentido común" extremadamente difundido y difícil de superar que permeabilizaba la mentalidad del jurista positivo. En virtud de éste, el juez tenía que limitarse a aplicar la ley, excluyendo el recurso a elementos y criterios de naturaleza diferente. La crítica desarrollada por la hermenéutica jurídica en relación con la teoría silogística niega la defendida automaticidad de la subsunción. ${ }^{11}$ En las teorias iuspositivas, la decisión del intérprete está latente en la disposición normativa, como una estatua en el bloque de mármol; por tanto, la conclusión del silogismo entre premisa mayor y premisa menor se plantea como una deducción automática.

Los presupuestos sobre los que se mueve esta teoría son dos. De un lado, que es el Estado, y más en concreto el legislador, quien tiene atribuida en exclusiva la producción del derecho; a su vez, existe una completa identificación entre derecho y ley que excluye otras fuentes que no sean la legislativa. Por otra parte, se entiende que el ordenamiento está completo, porque se concibe idealmente como algo preexistente, exento de lagunas y, por tanto, capaz de regular siempre todos los supuestos concretos con una norma. ${ }^{12}$

\footnotetext{
${ }^{11}$ Asi, por ejemplo, ESSER, JoSEF. Precomprensione e scelta del metodo nel processo di individuazione del diritto, SEA, Camerino, 1983, pp. 14 y ss.

${ }^{12}$ Este modelo positivista se desarrolla principalmente por medio de dos corrientes teóricas. La primera, teorizada en Francia por los juristas de la escuela de la exégesis, practicaba un método exegético basado en la predilección por la interpretación lógico-gramatical de las disposiciones normativas. Desde esta perspectiva, la interpretación
} 
La fuerte vinculación de estas teorías al tenor literal del texto y, por consiguiente, al elemento psicológico, las lleva a rechazar todo tipo de evaluaciones de orden teleológico que permitan al intérprete corregir el contenido de las disposiciones ampliando o limitando su portada. Esta tesis, según la cual el texto debe ser comprendido tan sólo sobre la base de los datos lingüísticos, se basa en el presupuesto de la objetiva univocidad del texto. Este presupuesto de base será derrumbado por la teoría de la interpretación jurídica elaborada en la segunda mitad del siglo xx, que niega la defendida automaticidad de la subsunción.

Con el fin de realizar el silogismo, no sólo es necesaria una actividad válida para conocer los posibles significados de un enunciado normativo, sino que también se requiere una elección de entre las posibles premisas mayores; una elección que implica necesariamente una valoración subjetiva.

El establecimiento de la premisa mayor y de la menor en los datos jurídicamente relevantes se configura como acto valorativo que excluye la posibilidad de atribuir a los procedimientos seguidos por los jueces la forma y el contenido de razonamientos puramente deductivos. ${ }^{13}$ De ahí que al legislador ya no se le reconozca una posición de absoluto monopolio, sino tan sólo de primacía en la formación del derecho.

Así las cosas, el juez participa estructuralmente en el proceso de formación del derecho, y se convierte en un elemento central del sistema jurídico. Se plantea de esta manera la necesidad de una nueva visión de la relación entre texto normativo y sentencia, y de la continua modificación de las normas

se considera como mera indagación y reproducción de un derecho preexistente; las disposiciones normativas pueden comprenderse exclusivamente sobre la base del texto y su aplicación a los supuestos concretos es tan sólo la exteriorización de un sentido univocamente definido por el legislador. Cuando el legislador no haya regulado de forma expresa el supuesto que se plantea al intérprete, las dificultades que se plantean se resolverán recurriendo al artificio de la voluntad "presumida" del legislador. La segunda, corriente teórica a la cual se aludia como continuación de la antigua tradición jurídica romana y de la Edad Media, nacida en Alemania, se difundió en Europa a través de la jurisprudencia de conceptos, que es una orientación metodológica desarrollada por los discipulos de Savigny en Alemania. Para estos teóricos, la actividad del intérprete consiste en reflejar y evidenciar los significados preconstituidos en las disposiciones normativas. La "jurisprudencia de conceptos" atribuye a los conceptos jurídicos y a la relación sistemática existente entre ellos el carácter de fuente de conocimiento. En ambos casos, a través del modelo iuspositivo de la interpretación, se llega a afirmar la posibilidad de una expansión lógica del derecho que permite considerar las soluciones de los supuestos concretos como conclusiones tautológicas de las disposiciones normativas consideradas capaces de llenar toda laguna. Véanse, BoвBio, Norberto. II positivismo giuridico, Cooperativa Libraria Universitaria Torinese Editrice, Turin, s.f., pp. 79-86; Prieto SANchis, LuIs. Ideología e interpretación jurídica, Tecnos, Madrid, 1987, pp. 19 y ss.

${ }^{13}$ A esta conclusión se llega desde el presupuesto de que el legislador no está autorizado para indicar de manera definitiva las reglas de utilización de las expresiones que él mismo usó. De esta manera, el nudo metodológico decisivo de la subsunción se considera el de la preparación de las premisas. ESSER, Josef. Precomprensione e scelta del metodo nel processo di individuazione del diritto, SEA, Camerino, 1983, pp. 48 y ss. Las premisas no están preconstituidas, y la complejidad de su preparación implica el recurso a juicios axiológicos guiados por evaluaciones previas del intérprete, relativas a la "razonabilidad" de la correspondencia entre dato normativo y dato de hecho. 
positivas en la praxis. Dentro de las técnicas para individualizar y aplicar el derecho en la praxis interpretativa del derecho continental codificado y en la anglosajona de los precedentes, emergen relevantes elementos comunes que conducen a la constatación de que la actividad del juez se transforma en elemento fundamental en la innovación del derecho, un momento esencial en la operación de reconocimiento y utilización del material jurídico. ${ }^{14}$

Este es el aspecto que de forma más directa entra en conflicto con las teorías positivistas tradicionales. Todas las tesis iuspositivistas sobre la interpretación deben ser reconducidas a un presupuesto fundamental: el del "estar en sí mismo" del derecho, es decir, el de la auto-consistencia del derecho positivo.

El derecho positivo debe poder contenerse, mantenerse y reproducirse por sí mismo, sin necesidad de recurrir a elementos externos, de naturaleza extrapositiva. Esto significa que el sentido del derecho positivo es inmanente al mismo y cabe deducirlo de los enunciados normativos existentes, definidos como derecho positivo.

Dicho planteamiento justifica la afirmación de la inexistencia de lagunas en el discurso legislativo y la contrariedad a todo elemento interpretativo de carácter iusnaturalista, ya que afirmar la existencia de principios extra-positivos significa negar el dogma del "estar en sí mismo". No obstante, esta tesis se sustenta tan sólo si se identifica el derecho con su forma, prescindiendo por completo del alcance de sus contenidos.

Refugiarse en el mero positivismo del derecho implica una actitud de autoconvencimiento equívoco, ya que equivale a aceptar que "el positivismo no puede comprenderse a sí mismo". ${ }^{15}$ De este núcleo fundamental se desprenden una serie de cánones sobre cuya base el modelo positivista ha articulado su perspectiva metodológica de la interpretación de la ley con la finalidad de evidenciar el monopolio del legislador en la producción del derecho.

Las diferentes doctrinas metodológicas vinculan la tarea interpretativa y de aplicación de las disposiciones normativas al texto, al contexto sistemático, a la voluntad del legislador, al sentido objetivo de la ley o a su finalidad. No obstante, las teorías que resuelven la interpretación como problema de sistema-

\footnotetext{
${ }^{14}$ ZaccaRIA, GIovannI. "Precomprensione e controlli di razionalitá nella prassi del giudice", Rivista de diritto civile, No. 30, 1984, pp. 313-321.

${ }^{15}$ Así Jaspers, Karl. Philosophie, Springer, Heidelberg, 1956, p. 220. Baste considerar que el permanecer anclado a nivel de la ley positiva presupone necesariamente una premisa extra-positiva que motive la autoridad del legislador. De esta manera, la extrapositividad rechazada vuelve a estar contenida en los presupuestos no expresados de estas teorías. El modelo positivista entiende el carácter normativo del ordenamiento como algo intrínseco; por estas razones, el positivismo realmente consecuente consigo mismo tendría que limitarse a describir la existencia del derecho sin afirmar su obligatoriedad. En este sentido, véase Viola, Francesco. I/ diritto como pratica sociale, Jaca Book, Milán, 1990, pp. 54 y 55.
} 
tización del uso de métodos no son de gran ayuda. La investigación limitada a los métodos por sí solos es improductiva, ya que la interpretación aparece como problema de elección de métodos tan sólo cuando a un método le corresponde una determinada visión ontológica del derecho; en este caso, el método no está en función de la decisión adecuada para un determinado supuesto, sino de la naturaleza del derecho que se quiere defender. Cuando la imposición de un método exclusivo o casi exclusivo se sustituye por un catálogo de métodos puestos a disposición del intérprete, se hace paulatina la incertidumbre acerca de la propia naturaleza ontológica del derecho.

El reconocimiento de la indiferenciada utilidad de una multitud de métodos pone al derecho en relación con diferentes exigencias sociales a las cuales debe dar respuesta y deja necesariamente abierto al intérprete un espacio de libertad. Tanto la ley como la Constitución, dotadas ambas de fuerza normativa vinculante, representan una etapa del proceso de concretización del derecho; un producto "casi acabado" que sólo ignorando la contribución decisiva de quienes aplican el derecho puede ser confundido con un producto verdaderamente ultimado. ${ }^{16}$

El hecho de que cada supuesto concreto donde ha de ser aplicada requiere una interpretación particularizada de la norma da lugar a un proceso que no se limita a explicar el enunciado normativo considerado de manera abstracta, sino que lo transforma en regla concreta de decisión. La verdadera interpretación, al igual que la ciencia del derecho, consiste, por tanto, y se resuelve siempre, en la necesaria extensión del texto jurídico positivo: una extensión definida por el condicionante que representa la comprensión del texto dispositivo en relación con el caso por decidir. Esto significa que "el discernimiento del sentido de un texto normativo y su aplicación al supuesto concreto no son dos actos separados sino, al contrario, un proceso único". ${ }^{17}$

Por tanto, la hermenéutica jurídica se define teóricamente por el reconocimiento de que la norma abstracta revela una estructura necesariamente incompleta, que se perfecciona tan sólo en el procedimiento hermenéutico de concretización que encierra toda decisión de un determinado supuesto práctico. Decisión y norma representan los elementos metodológicos más idóneos para comprender el funcionamiento del fenómeno jurídico en los ordenamientos contemporáneos y en la hermenéutica jurídica. Momentos de decisión y procesos interpretativos se enlazan de diferentes maneras. ${ }^{18}$

\footnotetext{
${ }^{16}$ La expresión "semilavorato", traducida por la autora como "casi acabado", es utilizada por MerKL, Adolf. // duplice volto del diritto, Cedam, Milán, 1987, p. 306.

${ }^{17}$ Asi Gadamer, Hans George. Ermeneutica e metodica universale, Giapichelli, Turín, 1973, p. 361.

${ }^{18}$ Catana, Antonio. Decisione e norma, ESE, Nápoles, 1979, pp. 158 y 159.
} 
Si, de un lado, ningún proceso interpretativo llega a excluir momentos de decisión, del otro, ninguna interpretación constituye decisiones, sino tan sólo una elección realizada dentro de un procedimiento interpretativo. El reconocimiento de este sutil e inestable enlace entre interpretación y decisión acaba, por una parte, con la perspectiva del logicismo -según el cual desde premisas estables se llega a la decisión a través de etapas metodológicamente impuestas-; por otra, con la perspectiva puramente decisionista -la cual defiende que la aplicación judicial constituye la sede de decisiones meramente creativas por parte del intérprete con el consecuente rechazo total de la dogmática-.

El objetivo común de las posiciones jurídico-hermenéuticas es superar el error de la metodología jurídica del positivismo tradicional, el cual concibe y presenta al derecho como "producto ultimado". Su aplicación sólo supondría la reproducción de un significado completamente establecido una vez por todas. La solución que ofrece el positivismo jurídico asume un concepto de derecho intrínseco al dato dispositivo sobre la base del cual se deben traducir los momentos valorativos donde tienen alguna incidencia los factores extralegales, en la ficción de la solución preestablecida. No obstante, con el fin de desarrollar el silogismo, se hace necesaria no sólo la actividad de discernimiento capaz de identificar los posibles significados de un enunciado dispositivo, sino también la elección entre las posibles premisas mayores. Esta elección siempre comporta una evaluación.

De esta manera, rechazada, por lo menos en términos generales, la doctrina silogística del iuspositivismo, pueden considerarse más convincentes las argumentaciones del planteamiento empírico-analítico. Existe un vínculo esencial entre procedimientos hermenéuticos y procesos lingüísticos y esto es así porque, por un lado, la interpretación jurídica requiere la adecuada comprensión del medio lingüístico por parte del juez; por el otro, la decisión debe motivarse de forma adecuada, a través del medium lingüístico, en atención al entorno donde se encuadra. ${ }^{19}$ El juez no se limita a pensar y argumentar para sí mismo; debe comunicar y hacer que sean plausibles los resultados conseguidos a través de sus argumentaciones.

En la metodología jurídica se ha elaborado la distinción entre "metodología de métodos" y "metodología de resultados". ${ }^{20}$ Mediante la primera, el intérprete elige los resultados sobre la base de los métodos; en virtud de la segunda, elige antes el "mejor" resultado y luego motiva sobre la base de los métodos que pueden conducir a él. En otras palabras, los métodos hermenéuticos pueden ser

\footnotetext{
${ }^{19}$ ESSER, Josef. Precomprensione e scelta del metotodo nel proceso di individualizzazione del diritto, op. cit., pp. 45 y sS. y 130 y ss.

${ }^{20}$ Lombardi Vallauri, Luigi. Corso de filosofia del diriritto, Cedam, Padúa, 1981, p. 79.
} 
más o menos apropiados, pero dado que deben ser aplicados en condiciones de incertidumbre relacionadas con el contexto donde han de aplicarse las disposiciones normativas, no pueden estar dotados de certeza absoluta. La existencia de una pluralidad de métodos, aun cuando el legislador los establezca y se utilicen según un orden impuesto al intérprete, implica una incertidumbre.

Las metodologías de utilización de los criterios de interpretación conducen a varios resultados posibles; si el intérprete sigue el tenor literal de la disposición, su ratio objetiva o la voluntad del legislador, los resultados son diferentes. Las metodologías de interpretación elaboradas teóricamente no logran predeterminar de forma univoca el proceso interpretativo. Se requiere siempre una decisión previa de aquél para seleccionar entre los diferentes métodos de interpretación los que, según su criterio, sean más idóneos para solucionar un determinado supuesto de hecho. Consideraciones como éstas han llevado a afırmar la invalidez de un catálogo de criterios interpretativos, como el elaborado por Savigny como límite a la libertad del intérprete. ${ }^{21}$

No obstante, si no se quiere reconducir la elección entre los criterios de interpretación a una cuestión de pura casualidad, en el centro de la doctrina del método debe situarse la cuestión clave de cómo elegir razonablemente entre los distintos métodos, es decir, la inteligibilidad de los motivos que están en la base de la decisión sobre la importancia de la preferencia por un determinado criterio interpretativo. La crítica al pluralismo de los métodos puede mitigarse afirmando que los criterios interpretativos, aunque desmitificados, mantienen su valor, pues el intérprete debe orientarse a través de ellos; si bien las reglas tradicionales de interpretación no pueden aislarse como métodos de interpretación autónomos y autosuficientes (si han de utilizarse conjuntamente), mantienen su función al ser un complemento necesario del proceso de aplicación del derecho. ${ }^{22}$

La circunstancia de que en la interpretación del juez pueda reconocerse un margen de integración valorativa y creativa no significa que se pueda legitimar el uso arbitrario de los métodos de interpretación o que deje de existir la obligación del juez de interpretar utilizando criterios razonables y controlables. ${ }^{23}$

\footnotetext{
${ }^{21}$ ESSER, Josef. Precomprensione e scelta del metodo nel processo di individuazione del diritto, op. cit., pp. 120-124.

${ }^{22}$ Monateri, Pier Giuseppe. "Interpretazione del diritto", Digesto delle discipline privatistiche, vol. 10, utet, Turín, 1993, p. 55.

${ }^{23}$ Lo que caracteriza la posición y el intento programático de la hermenéutica jurídica entre las teorías contemporáneas de la interpretación del derecho es su fuerte inclinación hacia una racionalidad controlable y discutible de la aplicación de la norma. Las principales teorias hermenéuticas del derecho, desde Esser a Müller, se empeñan en demostrar que entre el texto de una disposición y la específica solución judicial de un supuesto concreto no existe un vacuum absoluto que racionalmente no puede ser colmado; ya que todos los procedimientos de aplicación y producción jurídica pueden ser lógicamente controlados. Desde este punto de vista, una metodología jurídica como la hermenéutica, que reflexiona sobre la praxis revelando lo que ocurre en el concreto trabajo de aplicación de las disposiciones
} 
La relevancia del elemento metodológico en la tarea interpretativa no se limita a la perspectiva de la racionalidad sino que abarca también un elemento de carácter político. En este sentido, las disposiciones normativas que conforman el derecho se traducen en normas de aplicación por medio de decisiones que no se producen, en línea de principio, según los procedimientos democráticos propios de su elaboración.

Por estas razones, es aún más fuerte la exigencia de someter a verificación el método de trabajo del intérprete y a una valoración crítica su racionalidad, con el fin de garantizar que la decisión jurisdiccional no sobrepase, transgrediéndolos, los textos dispositivos, y no altere, por tanto, mediante la atribución al poder jurisdiccional de poderes impropios, las garantías impuestas al juego político democrático.

No obstante, ¿a quiénes debe estar atribuido el control de los métodos de individualización de las normas? Analizando desde una perspectiva histórica el desarrollo de la cultura jurídica moderna, el "método jurídico" fue elaborado originariamente por la doctrina que representaba y estructuraba una opinión científica orientada hacia la búsqueda de una idea de "método científico correcto", independiente de la praxis judicial y politicamente fiel a una determinada visión del derecho y de sus finalidades.

\section{Método, teoría del derecho e interpretación constitucional}

La opción por el método tiene, claramente, dos componentes: uno científico y otro ideológico. Desde la primera perspectiva, es frecuente en los últimos tiempos oír a constitucionalistas que se inclinan por el "método jurídico", una afirmación que debería despertar una estupefacción similar a la que se suscitaría en un químico, un médico o un arquitecto si un colega suyo señalara que se propone seguir, respectivamente, el método químico, el médico o el arquitectónico.

En esa afirmación subyacen dos equívocos. El primero de ellos es una confusión entre el método y el objeto. Lo que se quiere decir al manifestar inclinación por el inexistente método jurídico es que se va a hacer derecho, y

por parte de los intérpretes, puede desarrollarse coherentemente en dirección a una lógica de la concretización del derecho capaz de relacionar normas y hechos jurídicos según reglas metódicas reconocidas. La hermenéutica, como teoría postpositivista del derecho, comparte con las actuales teorías del razonamiento jurídico -baste con citar a Peczenick, Aarnio o Alexy- el intento de individualizar criterios objetivos de "razón juridica". Se caracteriza por perseguir la estructuración y racionalización de los ineludibles instrumentos de interpretación, sin contraponer norma y disposición, y proponiendo un método racional para controlar un espacio naturalmente abierto a sugestiones decisionistas. Para un análisis de las principales teorías contemporáneas de la interpretación, con especial atención a las relaciones entre tópica juridica, hermenéutica jurídica y teoría de la argumentación, véase ZACCARIA, GIACOMO. L'arte dell'interpretazione. Saggi sull'ermeneutica giuridica contemporanea, Cedam, Padua, 1990, pp. 16 y ss. 
no otra cosa. En segundo lugar, late también una inconsciente identificación entre el método jurídico y la dogmática; pero ya se ha visto, y es de sobra conocido, que la dogmática no es la única forma, ni siquiera la única forma jurídica, de aproximarse al derecho. ${ }^{24}$

Ciertamente, la dogmática, como conjunto coherente y delimitado de los preceptos que caracterizan a un ordenamiento jurídico, es una referencia metodológica inevitable: es, en realidad, la matriz de todos los enfoques de aproximación al derecho. Como apuntó Tomás Villarroya, "la dirección dogmática nos dejó un cuadro de conceptos y categorías cuyo uso puede sernos todavía de valor inestimable". ${ }^{25}$ Pero una metodología para el derecho no puede reducirse al método jurídico, porque la opción metodológica es también, no cabe ocultarlo, ideológica o, por decirlo menos abruptamente, valorativa.

Es ideológica, desde luego, la opción por el iusnaturalismo porque, so pretexto de lo inmanente, desprecia la voluntad -y, por tanto, la soberanía- popular; lo es la opción desnuda por el positivismo, porque, so pretexto de limitarse a lo dado, a lo reflejado en la norma, haciendo abstracción de quien la elabora o de cuál sea su contenido, desprecia tanto la voluntad y la soberanía popular como los valores inherentes a la dignidad humana; lo es, por último, la opción por la tendencia valorativa, porque la elección de unos u otros valores, o la determinación de las prioridades entre ellos es, a fin de cuentas, una elección personal igualmente ajena a la voluntad popular.

La cristalización de un Estado democrático de derecho que propugna como valores superiores del ordenamiento la libertad, la justicia, la igualdad, el pluralismo y la interculturalidad ofrece, sin embargo, una perspectiva de superación de esta situación. En cuanto que el derecho, de ser ciencia, es la ciencia de la norma, difícilmente puede tener como base algo que no sea la norma misma. Los datos básicos del derecho son los positivos, proporcionados por las normas. Ello hace del normativismo, especialmente el kelseniano, una referencia ineludible del método positivista. Son, también, datos extraíbles de los mecanismos técnicos y conceptuales ideados para la correcta aplicación de la norma y para el aseguramiento de su observancia.

Pero en cuanto que el derecho en general pretende ser la búsqueda, más que la realización, de la justicia, difícilmente se puede prescindir de esos valores. Como ha señalado La Torre, "demasiado fuerte es el peso de los derechos fundamentales, de los principios e incluso de los valores en los modernos Estados

\footnotetext{
${ }^{24}$ Asi, Troper señala que "el método jurídico es, simplemente, la dogmática". TROPER, Michel. Le constitutionnalisme entre droit et politique, p. 88. [En línea]. Disponible en: https://www.u-picardie.fr/curapp-revues/root/29/troper.pdf ${ }^{25}$ Villarroya, Joaquin Tomás. "La dirección dogmática en el derecho político", Revista de administración pública, No. 79, 1976, p. 69.
} 
constitucionales como para que sea posible continuar defendiendo una mera teoría legalista de la decisión judicial. ${ }^{26}$ La incorporación, realizada por la Constitución, de los valores a la norma permite ya que el jurista se centre en la norma sin por ello obviar los valores. El normativismo positivista, en cuanto que método de aplicación de una norma que incorpora valores, adquiere así un nuevo sentido.

Es verdad que esta tesis desplaza el problema al caso concreto, a cada supuesto concreto de aplicación de la norma y de los valores en ella recogidos. Pero este no es ya un problema metodológico: es, si acaso, un problema interpretativo, casuísticamente materializable, pero situado en un estadio donde se ha superado la antítesis norma-valores. El problema no es ya elegir entre aquella y éstos, sino determinar cómo aquella, en cada caso singular, los concreta y prioriza. Es, en suma, un problema hermenéutico, no de opción global.

La certidumbre de que la norma emana de una representación popular libremente elegida, de que respeta en todo caso los derechos fundamentales, de que, si no es así, hay mecanismos para evitar sus efectos perversos y de que, en suma, está sometida, según los casos, al control jurisdiccional ordinario o constitucional despeja las posibles dudas sobre su aceptación como norma válida.

Por todo ello, el método elaborado por la doctrina se orienta siempre en razón de la naturaleza del punto de vista adoptado y utiliza, de entre los métodos interpretativos, aquellos que resultan esenciales con el fin de garantizar una interpretación coherente con la visión o función del derecho que teóricamente quiere ser preservada; no obstante, el método orientado a la aplicación práctica de las disposiciones normativas no puede gozar, en principio, de un análogo espacio de libertad, ya que debe respetar aquellas limitaciones implícitas en la posición que, en un determinado ordenamiento, ocupa el intérprete en relación con las disposiciones por interpretar. ${ }^{27}$

No obstante, "los esfuerzos teóricos sobre los métodos [...] tienen algo de donquijotesco", ${ }^{28}$ ya que la elaboración de teorías de la interpretación no puede cumplir con la función de adaptar el orden de criterios elaborados por la doctrina a la praxis interpretativa. Esta última sólo puede autovincularse a un método jurídico determinado por las exigencias y las necesidades prácticas, y destinado a conseguir la aplicación del derecho a partir de la ley y de la Constitución.

\footnotetext{
${ }^{26}$ La Torre, Massimo. "Derecho y conceptos de derecho", Revista del Centro de Estudios Constitucionales, No. 16, 1993, p. 78.

${ }^{27}$ Habermas, Jürgen. Facticidad y validez, Trotta, Madrid, 1998, pp. 269 y ss.

${ }^{28}$ Véase Zagrebessky, Gustavo. El derecho dúctil. Ley, derechos, justicia, Trotta, Madrid, 1997, p. 137.
} 
El intérprete utiliza siempre una composición sincrónica de los diferentes tipos de interpretación que casi nunca operan como métodos autónomos, sino como construcciones metódicas que traen su origen de la compleja composición de los principales elementos que caracterizan a cada uno de ellos. Este necesario sincretismo debe, no obstante, estar caracterizado por su racionalidad, como único elemento capaz de garantizar que la decisión jurisdiccional no sobrepase las funciones que el ordenamiento democrático le ha asignado, y que, aun siendo siempre opinable, el modo de funcionar del razonamiento jurídico justifique la adopción de una u otra solución interpretativa.

A este respecto, y en relación con sus peculiaridades, el problema del método en la interpretación constitucional necesita de algunas consideraciones específicas. A través de los textos constitucionales contemporáneos y de su interpretación, se introducen en el ordenamiento una serie de valores éticopolíticos que preexisten al mismo pacto constitucional: aquellos valores que identifican la especificidad constitucional de un ordenamiento social y jurídico y que están incluidos en la mayoría de los casos en las disposiciones de principios o en los catálogos de derechos.

La institucionalización de estos valores morales, es decir, su introducción en el derecho positivo como "parámetros ideales" de cada ordenamiento, hace que se pueda hablar de su doble vigencia, porque siguen teniendo validez desde el punto de vista ético y como principios jurídicos. ${ }^{29}$

Esto hace que el entramado normativo-constitucional presente características específicas constituidas por su carácter axiológico, su indeterminación y su reducida intensidad prescriptiva. ${ }^{30}$ La laxitud semántica de las disposiciones constitucionales y su relación estructural con los valores políticos conllevan una vinculación menos rigurosa para el intérprete; por tanto, demandan un control más atento por parte de la doctrina, en comparación con lo que ocurre en sectores del ordenamiento más técnicos. No puede olvidarse que la Constitución es un acto normativo que contiene disposiciones preceptivas. Por ello, los jueces constitucionales, en su función de intérpretes autorizados por la Constitución, y como jueces de la constitucionalidad de las leyes, deben considerarse, si bien es cierto que de una forma menos apremiante que en el caso de interpretación de la ley, como vinculados al texto constitucional.

Es cierto que, en relación con los métodos interpretativos utilizados en otros sectores del derecho, donde el recurso al esquema silogístico es más amplio, el método de la interpretación constitucional se sustancia en argumentaciones

\footnotetext{
${ }^{29}$ Dworkin, Ronald. Los derechos en serio, Ariel, Barcelona, 1984, pp. 274 y ss.

${ }^{30}$ RugGerI, ANtonIo. "L'identitá costituzionale alla prova: i principi fondamentali fra revisioni costituzionali polisemiche e interpretazioni-aplicazioni 'ragionevoli'", Ars interpretandi, No. 1, 1996, pp. 113-129.
} 
basadas en principios y valores contenidos en normas cuya aplicación no asume la forma silogística de la subsunción, sino la de la optimización de la realización del precepto. ${ }^{31}$ Por esta razón, valores y principios pueden entrar en concurrencia. Aun considerados singularmente, pueden encontrarse en una situación de conflicto que implica la necesidad, para el intérprete, de resolver la colisión caso por caso, decidiendo sobre la base de una jerarquía puntual que tan sólo en un determinado contexto aplicativo se traduce en la prioridad de un principio respecto de otro.

Esto hace que la interpretación de los enunciados constitucionales deba, por un lado, garantizar la firmeza de un núcleo que identifique el valor originariamente garantizado y, por el otro, cubrir la necesidad de que dichos enunciados, a través de una razonable variedad de interpretaciones y de aplicaciones, sean continuamente remodelados para adecuarlos a las innovaciones históricopolíticas y a las mutaciones de los propios significados sociales.

Todos estos principios y valores se encuentran en la base de las Constituciones, que representan un compromiso entre conservación y renovación; cuya imprescindible y continua adaptación a las mutaciones sociales se traduce necesariamente en una función que uno de los poderes constituidos debe desarrollar. La escasa utilización del instrumento de la reforma constitucional, así como las dificultades implícitas en la cristalización e individualización de conceptos en los cuales obligatoriamente deben incluirse y compatibilizarse diferentes concepciones, hace que la Constitución sea a la postre el resultado de la interpretación de las disposiciones contenidas en ella; es decir, el resultado de un "círculo hermenéutico" entre valores y principios conformadores de la sociedad.

Si a esto se añade que en algunas ocasiones la intervención de los jueces constitucionales se configura en términos que, desde el punto de vista cualitativo, no difieren de los del poder legislativo, innovando e integrando los textos dispositivos, ${ }^{32}$ no es difícil constatar que las orientaciones interpretativas se mueven en un terreno condicionado por la concreta evolución de las comprensiones del sentido y de las relaciones entre las fuerzas sociales.

En este sentido, la hermenéutica y la actuación de la Constitución se suman y se integran en un conjunto unitario. Aún cuando los conflictos constitucionales tienen una indudable repercusión política, esta afırmación no puede traducirse en que su resolución no pueda sujetarse a criterios de derecho y a pautas jurisdiccionales. ${ }^{33}$

\footnotetext{
${ }_{31}^{31}$ MengonI, LUIGI. "II diritto costituzionale come diritto per principi", Ars interpretandi, No. 1, 1996, pp. 95-111.

32 Zagrebelsky, Gustavo. "Appunti in tema d'interpretazione e interpreti della Costituzione", Giurisprudenza Costituzionale, No. 15, 1990, pp. 907 y 908.

${ }^{33}$ Pérez Tremps, Pablo. Tribunal Constitucional y Poder Judicial, Centro de Estudios Constitucionales, Madrid, 1985, p. 14.
} 
La sutil complejidad que caracteriza a los mecanismos a través de los cuales los diferentes métodos de interpretación se combinan en la praxis interpretativa hace que las alternativas axiológicas implícitas en cada uno de ellos no resulten tan nítidas, evidentes y extremas como puede demostrarse si se realiza un estudio teórico. No obstante, aunque las antítesis entre los valores que inspiran los métodos en la praxis no resultaran ser inelegibles con la claridad que sería de desear, el estudio empírico de esta última debe considerarse como el único instrumento capaz de comunicar lo que exactamente se hace y cómo se hace en la praxis judicial. Con ello se puede deducir un conjunto de reglas metodológicas funcionales de la interpretación y a la precomprensión de la Constitución capaces de garantizar aquella seguridad jurídica implícita en la lógica de todo Estado constitucional que cimienta su estructura en el principio político democrático y en la supremacía constitucional.

En este sentido, incluso dentro de un concepto dinámico de Constitución en el cual, frente a la insuficiencia de los mecanismos agravados de reforma constitucional, se ha llegado a incluir el de "mutación constitucional" para prever y legitimar sus modificaciones informales, no puede ponerse en duda la noción de supremacía que implica la imposición de límites a la mutación para evitar que los poderes constituidos se transformen en efectivos poderes constituyentes. ${ }^{34}$

Si en la teoría de la interpretación el método jurídico no puede identificarse como método para "comprender" sino que se considera como método para "obrar", su validez y corrección pueden ser comprobadas sólo a través del análisis de la praxis. Como afirmaba Aristóteles, el método se desarrolla y se verifica practicándolo, pues lo que en última instancia sea se demuestra en su utilización. Lenguaje y acción, comprensión y decisión lingüística son una sola cosa, en este sentido, porque entender y comprender son partes esenciales del lenguaje pensado como ejercicio comunicativo y no como un conjunto de signos abstractos.

\footnotetext{
${ }^{34}$ El problema de los cambios informales de la Constitución fue destacado por la doctrina publicista alemana de finales del siglo xIx y principios del xx. Los primeros en tratar de forma directa este fenómeno fueron los autores de la escuela alemana de derecho público. Entre ellos, Lamband se planteó el problema de la mutación desde la constatación de que la Constitución puede transformarse fuera de los mecanismos formales de reforma, a pesar de ser "Ley" que debe dar continuidad y estabilidad al derecho en cuanto codificación de las elecciones fundamentales del Estado. Jellinek hizo referencia a las mutaciones constitucionales después de constatar que la rigidez constitucional, en muchos casos, constituye una garantia insuficiente para asegurar la fuerza normativa de la Constitución. No obstante, sólo por parte de la doctrina alemana de entre guerras hubo un intento de integrar el cambio constitucional informal en un concepto complejo de Constitución. Véanse, Jelunek, Georg. Reforma y Mutación de la Constitución, Cec, Madrid, 1991; Heller, Hermann. Teoría del Estado, FCE, México, 1981; Heller, Hermann. Escritos politicos, Alianza, Madrid, 1985; SMend, Rudolf. Constitución y Derecho constitucional, CEc, Madrid, 198; Hesse, KonRaD. "Concepto y cualidad de la Constitución", en Escritos de derecho constitucional, cec, Madrid, 1983.
} 
Si el significado está estrechamente ligado a la utilización de los enunciados, sólo podrá ser individualizado con referencia a la intención de los que utilizan este lenguaje y dentro del juego lingüístico en cuestión, ya que no se trata de una utilización privada sino de una utilización pública de las palabras o de otros signos. Este uso necesariamente debe ser conforme con unas reglas de las cuales dependerá la comprensión de las intenciones del intérprete, del tipo de actividad que desarrolla y de las razones que pueden legitimar los resultados de la aplicación de una determinada argumentación jurídica. ${ }^{35}$

Las motivaciones del juez constitucional deberían fundamentarse desde el punto de vista metodológico; en caso contrario, frente al relativismo de la interpretación, sería ineficaz el propio significado jurídico de la jurisprudencia constitucional y se vería comprometido el papel institucional que el Tribunal Constitucional debería desarrollar como intérprete máximo, que no único, de la norma suprema. ${ }^{36}$

\section{Teorias deductivo-demostrativas y tópico-retóricas y naturaleza de la decisión del Tribunal Constitucional}

Las investigaciones dirigidas a una valoración de la coherencia interpretativa del organo encargado de la jurisdicción constitucional deben, no obstante, tener en cuenta la existencia de una profunda diferenciación entre teorías positivistas y tópicas del razonamiento jurídico.

Con el fin de justificar el ámbito donde puede desarrollarse el estudio de los instrumentos interpretativos de algunas normas consitucionales, es necesario hacer alusión a las motivaciones de las decisiones judiciales en general. En las sociedades antiguas, no se exigía la motivación de las sentencias, ya que el órgano creador del derecho era el único legitimado para interpretarlo; consecuentemente, no era necesario llevar a cabo un control ni social ni institucional respecto de la actividad interpretativa.

Sin embargo, en los ordenamientos jurídicos modernos, en los cuales se garantiza una separación entre el legislador y los órganos que aplican el derecho, la obligación constitucional de motivar todas las decisiones judiciales resulta imprescindible para de asegurar una justificación que pase por un razonamiento. En este sentido, motivar una decisión judicial significa proporcionar argumentos que la sostengan. ${ }^{37}$ A este respecto, la lucha secular entre las teorías positivistas y

\footnotetext{
${ }_{35}$ WitTGENSTEIn, Ludwig. Ricerche filosofiche, Einaudi, Turin, 1974, p. 87.

${ }^{36}$ Alexy, Robert. Teoría de la argumentación jurídica, CEC, Madrid, 1997, p. 20.

${ }^{37}$ WróblekY, Jerzy. "Motivation de la décision judiciaire", en Perelman Chaïm, P. Foriers (Dir.). La motivation de la
} 
el razonamiento jurídico sobreentiende un conflicto político en orden al margen de libertad del juez y su capacidad de crear nuevas normas jurídicas. ${ }^{38}$

Semejante disputa, sin embargo, nunca tendrá un vencedor porque siempre es posible la coexistencia entre tópica y lógica formal, ya que no existen ordenamientos en los cuales se encuentren positivizadas todas las reglas necesarias para disciplinar las infınitas tipologías de relaciones que pueden darse entre los conciudadanos, ni ordenamientos dejados a la indeterminación de una jurisprudencia casuística, o extraña a todo tipo de reglas deductivas. En cada sentencia de cada juez se pueden encontrar siempre componentes retóricos y demostrativos, y la relación entre ellos cambia al variar las especificidades político-culturales de los diferentes ordenamientos, de la tradición jurídica nacional y de la peculiaridad de las singulares disciplinas jurídicas. ${ }^{39}$

Aunque asignando a las argumentaciones tópicas un papel marginal y subsidiario en la economía de la estructura de las decisiones jurisdiccionales, ${ }^{40}$ puede afirmarse que, en el caso de las decisiones de los órganos de justicia constitucional, se interviene en el ámbito más hostil a las argumentaciones de tipo lógico formal y, por consiguiente, la tópica jurídica tiene su más amplia posibilidad de afirmación.

décision de justice, Bruylant, Bruselas, 1978, p.111. La sentencia motivada encuentra sus orígenes como limite a la arbitrariedad del juicio caracteristicas del ancien regime para consentir el control sobre la administración de la justicia. El primer caso en el cual se evidencia una obligación formal de motivación de las sentencias es la praxis prusiana formalizada por el Codex Fridericianus, producto del despotismo iluminado de Federico II y que ya en el 1748 preveía la obligación para los jueces de motivar sus sentencias, asi como de las diferencias entre las razones que justifican esta obligación y aquellas que están en la base de la experiencia revolucionaria francesa. Véase TARufFo, Michele. "L'obbligo di motivazione della sentenza civile tra diritto comune e illuminismo", Rivista di diritto processuale, 1964, p. 295 y ss.

${ }^{38}$ En abierta y declarada polémica con el racionalismo cartesiano, la retórica, prototipo de todas las lógicas jurídicas, será considerada con el fin de demostrar que las argumentaciones de los juristas no sirven tanto como demostración more geometrico cuanto para persuadir a los destinatarios. Cfr. Perelman Chaïm, Olbrechts TYtecA, Lucie. Trattato dell'argimentazione. La nuova retorica, vol. 1, Einaudi, Turín, 1966, p. 9; Gavazzı, Glacomo. "Topica giuridica", en Nuovissimo digesto italiano, vol. 19, Turín, 1973, pp. 411 y 416 ss. Sobre el concepto de tópica, entendida como "técnica del pensamiento de problemas", es decir, como un pensamiento que opera por ajustes concretos para resolver problemas particulares partiendo de directrices que no son principios lógicos sino simples loci communes, de valor relativo, véase Vienweg, Theodor. Tópica y jurisprudencia, Civitas, Madrid, 2007. Define la tópica como "técnica del pensamiento problemático". Diez-PICAzo, Luis. Experiencia jurídica y teoría del derecho, Ariel, Barcelona, 1993, p. 265.

${ }_{39}$ BobBio, Norberto. "Sul ragionamento dei giuristi", Rivista di diritto civile, 1955, p. 3 y más recientemente en P. Comanducci y R. Guastini (dir.), L'analisi del ragionamento giuridico, Enaudi, Turin, 1989, p. 170. Las consideraciones de Bobbio se mueven en el ámbito de una concepción según la cual la función del jurista no es la de persuadir a los ciudadanos sino la de demostrar la "validez" de una determinada norma. Conducen a afirmar que "el razonamiento deductivo tiene un papel fundamental en la argumentación jurídica". Sin embargo, no alcanza a negar que "el razonamiento deductivo no agota todo el discurso jurídico" y que siempre hay un espacio argumentativo retórico para consideraciones de carácter histórico, sociológico, y cultural.

${ }^{40}$ Según Gavazzi, "el espacio de la tópica en el discurso jurídico es exactamente aquel en el cual la lógica es incompetente. Más allá de este espacio las pretensiones de la jurisprudencia tópica sobre la jurisprudencia racional esconden sencillamente una lucha de poder, llevada a cabo disimuladamente, con el de fin de repartir la competencia para emanar normas jurídicas". Gavazzı, Gıacomo. Op. cit., p. 418. 
Esto es así por una serie compleja de factores concurrentes; entre ellos, por la exigua base positiva a disposición del juez constitucional a la hora de resolver un determinado conflicto. Dicha característica, unida con la circunstancia de que, en las mayoría de los casos, las Constituciones se limitan a enunciar valores o principios en términos absolutos, tiene como consecuencia que el nivel de abstracción y generalidad de las motivaciones del Tribunal Constitucional es, en hipótesis, máximo, y obliga a este órgano a una labor de normación, continúa escondida por mucho tiempo bajo el mítico simulacro de la sentencia neutral con la que se aplica el derecho ya existente. ${ }^{41}$

Consecuentemente, la sentencia constitucional se sitúa dentro de los actos jurisdiccionales, es decir, entre los actos que en hipótesis son únicamente aplicativos de un derecho ya existente, como la sentencia que, sin embargo, está dotada del máximo contenido normativo. El Tribunal, en la mayoría de sus decisiones, aplica normas plasmadas por él mismo, sirviéndose del inacabado material puesto a su disposición por la Constitución. En la mayoría de los casos, dicho material se limita a enunciar un principio o un valor, prácticamente inservible si es utilizado sólo con los instrumentos de la lógica formal.

Si alguien ha llegado a creer en el mito del juez como bouche de la loi, nadie ha podido defender que el mismo pudiera ser el juez de las leyes. La motivación de la sentencia constitucional sirve, por tanto, casi siempre para justificar la decisión a la cual el Tribunal ha llegado no por silogismos deductivos realizados sobre precisas reglas formales, sino sobre la base de una norma que a veces no existe en el sistema con aquel mismo significado, y que viene deducida por el juez a través de un proceso lógico cuyas únicas premisas comprobables están constituidas por los valores y principios establecidos por la Constitución. ${ }^{42}$

Estas razones hacen que la motivación de la sentencia constitucional sea, de entre todas las motivaciones, la más "retórica”. Es el acto decisorio que más se sirve del método argumentativo para auto-fundamentarse racionalmente. ${ }^{43}$

La estructura tópica de la motivación de las sentencias constitucionales se constata con mayor evidencia allí donde el Tribunal Constitucional está llamado a decidir sobre materias respecto de las cuales es muy difícil justificar el juicio

\footnotetext{
${ }^{41}$ Kelsen, Hans. La giustizia costituzionale ,Giuffré, Milán, 1981, p. 174. Acerca de la utilización judicial de las normas constitucionales de principios o programáticas, ZagreBessky, Gustavo. La giustizia costituzionale, II Mulino, Bolonia, 1977, pp. 125 y ss.

${ }^{42}$ La reconstrucción de una teoria de los derechos fundamentales operada por Alexy se debe, tal y como el mismo autor defiende, al intento de eliminar la extrema vaguedad con la cual el catálogo de derechos fundamentales regula cuestiones sumamente discutidas de la estructura normativa básica del Estado, a la cual se suma la vaguedad de la jurisprudencia sobre los mismos. AleXY, RoBert. Teoría de los derechos fundamentales, op. cit., pp. 22-24.

${ }^{43}$ La función de los topoi en la interpretación constitucional relativa a los derechos fundamentales es demostrada por Bin, RoBerto. Diritti e argomenti. II bilanciamento degli interessi nella giurisprudenza costituzionale, Giuffre, Milán, 1992, pp. 4 y ss.
} 
en términos deductivos, bien porque las normas utilizadas son tan genéricas que no se prestan a convincentes operaciones deductivas, o bien porque se prefiere persuadir a los destinatarios en lugar de demostrar la exactitud de la decisión. ${ }^{4}$

En la primera categoría se sitúan un número muy elevado de casos en los cuales el Tribunal aplica normas que expresan principios y derechos constitucionales de los cuales no puede hacer una utilización en términos formales, dado que el propio "carácter abierto y su pluralismo" son un obstáculo insuperable para ello. ${ }^{45}$ Se trata de todas aquellas sentencias en las cuales el Tribunal utiliza principios o valores constitucionales que no se traducen en normas directamente preceptivas, sino que necesitan de una mediación deductiva para que el interprete las aplique concretamente. ${ }^{46}$

Estas conclusiones parecen inevitables si se considera la imposibilidad de una jerarquía formal entre los valores -tomando en cuenta además que cada uno tiende a ser absoluto-, lo cual provoca inevitables conflictos que deben solucionarse sin recurrir a la prevalecía de uno sobre otro, sino ponderándolos en cada caso. La medida de actuación de los principios constitucionales no se presta a ser teorizada en términos formales o deductivos. Es una cuestión que todavía depende de la apreciación del legislador y del Tribunal Constitucional. ${ }^{47}$

La aplicación de valores constitucionales no puede seguir "argumentos científicos", en los cuales destacan principalmente los aspectos cuantitativos y materiales de los elementos en discusión, porque "tan sólo en el campo jurídico, político y filosófico los valores intervienen como base de las argumentaciones en todo el curso del razonamiento y se apela a ellos para involucrar al oyente en una elección en lugar de otra y sobre todo para justificarlas y hacer que sean aceptadas y aprobadas por todos". ${ }^{48}$

\footnotetext{
${ }^{44}$ Bobbio analiza las diferencias entre juicio de valor y juicio de validez. Véase BoвBIO, NorberTo. "Sul ragionamento dei giuristi", Rivista di Dirito Civile, No. 1, 1955, p. 3.

${ }^{45}$ Zagrebelsky, Gustavo. El derecho dúctil, op. cit., p. 124.

${ }^{46}$ Describe el procedimiento de aplicación de un principio constitucional. ZagreBeLSKY, Gustavo. II sistema delle fonti del diritto, vol. 1, UTE, Turín, 1987, p. 107.

${ }^{47}$ AleXY, Robert. Teoría de los derechos fundamentales, op. cit. El autor pone en evidencia cómo "las reflexiones sobre la base de la argumentación iusfundamental estaban dedicadas a la cuestión de la controlabilidad racional de la argumentación iusfundamental. El resultado es que, en virtud de su base, la argumentación iusfundamental está, por cierto, algo más determinada y estructurada racionalmente, pero que la medida y la fuerza de control que con esto se logra son limitadas. Queda todavía una considerable laguna de racionalidad [...]. La inseguridad de resultado del discurso iusfundamental conduce a la necesidad de una decisión iusfundamental dotada de autoridad. Si la mayoría parlamentaria no ha de autocontrolarse, queda sólo la posibilidad de un Tribunal Constitucional, cualquiera que sea su forma. No tiene nada de irrazonable el hecho de que un Tribunal Constitucional no sólo argumente sino que también decida", p. 553. En el mismo sentido, haciendo referencia concretamente a la Primera Enmienda de la Constitución estadounidense, véase DworkIN, Ronald. Los derechos en serio, Ariel, Barcelona, 1984, pp. 211 y ss. ${ }^{48}$ Perelman, Chaïm, Olbrechts TyteCA, Lucie. Trattato dell'argimentazione. La nuova retórica, Einaudi, Turín, 1966, p. 80.
} 
Las grandes líneas del modelo teórico del razonamiento retórico, las razones de su utilización, sus posibilidades y los límites que lo separan del razonamiento lógico o teórico podrían resumirse hablando del mismo como de un método útil para investigar las circunstancias y los instrumentos de control de aquellas formas de pensar cuyo objetivo no son las conclusiones que se alcanzan mediante inferencia lógica, ni las generalizaciones que se confirman o desmienten por la experiencia, sino la justificación de opiniones y decisiones que se basan en la elección entre diferentes alternativas.

La argumentación lógica depende de normas, se basa en la coherencia y da lugar a resultados acertados o erróneos. El modelo retórico, en cambio, depende de valoraciones, tiene como dogma la plenitud, el juez está obligado a fallar en todo caso y sus conclusiones, a diferencia de lo que ocurre en la argumentación lógica, son débiles o fuertes. ${ }^{49}$

Esto no significa que exista un divorcio absoluto entre los dos métodos de argumentación, ni que el primero pertenezca al ámbito racional y el segundo remita a procesos irracionales, pero sí evidencia que las argumentaciones persuasivas, como todas las argumentaciones tópicas o retóricas, no muestran con suficiente claridad el origen último de los topoi en los cuales se basan. El origen de las premisas probables o puntos de vista sobre los cuales hay una opinión generalizada, y que se conciben como hilos conductores de una argumentación orientada a solucionar de modo justo un caso concreto para que se acepte en todas partes y se genere consensum omnium.

Que pueda tomarse una decisión racional a partir de valores o directamente del derecho natural puede demostrarse. Sin embargo, habría que preguntarse si estos criterios pueden ofrecer una cobertura de legitimidad análoga a la que proporciona la Constitución.

En este sentido, existen evidentes dificultades que puede presentar la racionalización de la motivación de las sentencias recaídas en el ejercicio de la función de garantía del Tribuanal Constitucional. Es decir, de una motivación, que puede encontrar su justificación tan sólo en la existencia de una determinada teoría de los conceptos de valores, que permita mantener la imagen de un juez vinculado por el dictado de las cláusulas constitucionales, aunque se llegue al entendimiento de estas últimas como meras apelaciones a conceptos morales. ${ }^{50}$

\footnotetext{
${ }^{49}$ Perelman, Chailm. "Raisonnement juridique et logique juridique", en Archives de Philosophie du Droit, vol. 11, 1966, pp. 1 y ss. ${ }^{50}$ Así los entiende Dworkin, Ronald. Los derechos en serio, op. cit., p. 216.
} 


\section{A modo de conclusión: interpretación dialógica y finalidad de la motivación de la sentencia constitucional}

La lógica de la argumentación, aunque sin inspirarse en criterios pertenecientes a una ideología estrictamente formal, pretende la correcta utilización de los argumentos interpretativos. Por tanto, no puede ceder al arbitrio de las decisiones, ya que una pretensión sólo puede ser legítima si se fundamenta en el marco impuesto por el ordenamiento en el cual el intérprete opera; mientras que atribuir la primacía al supuesto que se pretende resolver significa negar la primacía de la vinculación del intérprete al derecho.

En este sentido, como la doctrina ha puesto de relieve, si bien es cierto que el Tribunal Constitucional se encuentra obligado a aplicar aquellas disposiciones de compromiso en las cuales el constituyente haya remitido la responsabilidad de decidir a los jueces constitucionales, ejerciendo de esta manera una función constituyente por decidir alli donde el poder constituyente no ha decidido, es decir, actuando como comisionado suyo, no es más cierto que las normas constitucionales deben desarrollarse partiendo de la concepción de la Constitución como norma y no como simple proyecto o como reflejo de la realidad política subyacente. "La diferencia entre ambas posibilidades es en concreto la diferencia entre una jurisprudencia pragmática, sin una orientación uniforme, arrastrada por la necesidad del caso y por la consideración de las consecuencias de las sentencias y una jurisprudencia orientada por una razón jurídica". ${ }^{51}$

Frente a la exorbitante expansión de las funciones originariamente atribuidas al Tribunal a este nivel, el constitucional, resulta imposible plantear soluciones al conflicto entre lo fáctico y lo normativo, similares a las orientadas a resolver el nivel legislativo del desajuste entre teoría y praxis constitucional.

Los límites a su labor no pueden encontrarse en el nivel de las garantías abstractas, ya que en este sentido la Constitución no dice nada y es imposible plantear la previsión de ulteriores guardianes para vigilar al guardián de la Constitución. Frente a esta imposibilidad, queda un último baluarte: la verificación de la existencia de estructuras argumentativas lo suficientemente claras y constantes como para permitir la reconstrucción tipológica de los argumentos y de las estrategias argumentativas con el fin de delinear una teoría de la interpretación elaborada por el propio Tribunal. Además, debe considerarse como elemento de limitación o autolimitación del intérprete constitucional; por tanto, como fuente de su legitimación.

\footnotetext{
${ }^{51}$ Asi De 0тто, Ignacio. "Posición del Tribunal Constitucional a partir de la doctrina de la interpretación constitucional", en El Tribunal Constitucional, Instituto de Estudios Fiscales, Madrid, 1981, p. 1948.
} 
La constatación de la inexistencia de esas estructuras argumentativas haría que el Tribunal quedara libre de actuar como poder soberano. El único freno al constante desarrollo de sus poderes, tanto en sentido cuantitativo como cualitativo, podría encontrarse en el nivel sustancial del consenso ciudadano, de las demás instituciones y de los componentes sociales que constituyen la base legitimadora de tal poder.

Ante esta situación, la motivación de la sentencia constitucional sigue siendo el único instrumento de legitimación del Tribunal y del legítimo posicionamiento de éste en el sistema constitucional. Sigue siendo válida la consideración de que "el fundamento de la colocación preeminente o, como a veces se dice, de la legitimación del órgano encargado de la jurisdicción constitucional en la organización constitucional debe ser buscado, más que en las modalidades de su composición, en las modalidades bajo las que se desenvuelve su acción". ${ }^{2}$

La motivación constituye, pues, el índice principal de las modalidades de acción del Tribunal Constitucional; por tanto, el índice de su efectiva ubicación entre los demás poderes del Estado y en la relación entre las instituciones y el pueblo.

Una motivación que, como se ha demostrado, encuentra su primera garantía en el respeto por el Tribunal de un modus operandi que pueda hallarse por vía inductiva, y que reniega, por tanto, una legitimidad preconcebida. De ello deriva que "nunca está asegurada desde el principio, de una vez por todas, por un proceder de conformidad con competencias o normas previas, sino que postula, como condición imprescindible para poder mantener su papel, que su actividad esté orientada y guiada por la racionalidad". ${ }^{53}$

Esta racionalidad se entiende como coherencia entre jurisprudencia constitucional y valores compartidos por sus propios destinatarios. Obliga, por una parte, a volver a la relevancia de la motivación; por otra, a cambiar su finalidad. Pasa de considerarse un instrumento para controlar el respeto de unas reglas a ser un instrumento para la adquisición de consenso, con el fin de legitimar cotidianamente la acción del Tribunal Constitucional y con el de la "Constitución viviente" continuamente remodelada por este órgano.

El hecho de que ya no exista (o exista de manera cada vez más débil) un ámbito fuerte de legitimación unitaria desplaza radicalmente los términos de la "cuestión Tribunal Constitucional". Subsiste una creencia generalizada de racionalidad respecto del valor; pero también se oponen a lo anterior creencias de diferente tipo que relativizan el aspecto de derivación del valor y dirigen la mirada, cada vez con más decisión, hacia el resultado.

\footnotetext{
${ }^{52}$ Angiolni, VITtorio. "La Corte senza il 'processo', o il 'processo' costituzionale senza processualisti?", en La giustizia costituzionale ad una svolta, Giappichelli, Turín, 1991, p. 25.

${ }^{53}$ Mezzanotie, Carlo. Corte Costituzionale e legittimazione politica, Tipografia Veneziana, Roma, 1984, p. 134.
} 
La consideración del resultado, que antes era tendencialmente absorbida por la idea de un a priori constitucional en la metodología prescriptiva que esta idea comportaba, es ahora tan sólo una etapa en el itinerario de legitimación del juez de las leyes. Ante esto probablemente haya que asumir que en estos momentos el constitucionalismo moderno ha llegado a aquella fase de responsabilidad política difundida a la cual el Sandulli miraba con simpatía ya en 1958, cuando hablaba de control directo de la opinión pública sobre la jurisprudencia. ${ }^{54}$ No obstante, a esta fase no puede llegarse siguiendo un camino que pretende esconder todavía la realidad detrás de los falsos velos de las ideologías.

Si el único recurso para defender a la Constitución del arbitrio de su vigilante es un control difuso, una opinión pública crítica con la jurisprudencia, dicha opinión sólo puede crearse a través de un debate que intente poner de relieve la debilidad conceptual de algunas de las ideas sobre las que cimenta su estructura el Estado constitucional, es decir; el principio político democrático y el principio jurídico de supremacía constitucional.

Si se considera que la contraposición existente entre el principio legitimador de la soberanía popular y la teoría de la limitación del poder, que implica el entendimiento de la Constitución como ley suprema, manifiesta su más fuerte ambigüedad en la asignación al pueblo de la facultad de dictar y aprobar una Constitución que, aun siendo expresión de su soberanía, no es óbice para que el dogma de la soberanía popular y el poder constituyente, una vez realizada su obra, desaparezcan como tales ${ }^{55}$ y permitan la consideración del Tribunal Constitucional como "legislador constituyente" o "constituyente permanente". Éste difícilmente puede encajar en el esquema teórico anteriormente descrito, lo cual obliga, por tanto, a volver a discutir sobre los conceptos de supremacía constitucional y rigidez de la norma fundamental.

Existe "una ingente masa" que no comparte la tendencia dominante y queda inerme y desconcertada. Una masa que no acepta lo existente y desconoce los cauces hacia el cambio. Hacia esta dirección se mueve el estudio aquí llevado a cabo, sin pretensión alguna de plantear soluciones definitivas, pero sí con la voluntad de llamar la atención sobre la inexistencia de algunos de los baluartes sobre los cuales se funda el Estado constitucional y la necesidad de que los juristas, y más concretamente los constitucionalistas y la "opinión pública constitucional”, se comprometan a consolidar (o tal vez a reconstruir)

\footnotetext{
${ }^{54}$ Sandulli, Aldo MazzinI. "Natura funzione ed effetti delle pronuncie della Corte costituzionale sulla legittimità delle leggi", Rivista trimestrale di diritto pubblico, No. 1, 1959, p. 25; de la misma opinión es Rodotá, Stefano. "La svolta politica della Corte costituzionale", Politica e Diritto, No. 2, 1970, p. 37.

${ }^{55}$ De Vega, Pedro. La reforma constitucional y la problemática del poder constituyente, Tecnos, Madrid, 1985, p. 20.
} 
una "visión constitucional", volviendo a descubrir y evidenciar el papel de los valores compartidos y las bases de sentido sobre las cuales se funda el Estado constitucional.

Tal vez haya llegado el momento de retornar para promover un nuevo Estado constitucional plural y democrático, tal vez sea hoy necesario entender las capacidades persuasivas de los juristas al servicio de la promoción de este Estado constitucional, y si esto es así deberá renunciarse a los meros análisis descriptivos de la realidad político-constitucional para empeñarse en los más escabrosos terrenos de las reconstrucciones de carácter prescriptivo, aunque esto implique la construcción de una nueva teoría de la Constitución.

Tal vez ha llegado el momento de promover, recogiendo el espíritu de todos aquellos que en su día hicieron de la crítica jurídica un instrumento de análisis que habría que dignificar, en última instancia, nuestra convivencia social, la reconstrucción de un nuevo Estado constitucional sustentado en la interculturalidad y en el principio democrático. 